\title{
CARBON DIOXIDE ON THE EARLY EARTH
}

\author{
JAMES C. G. WALKER \\ Space Physics Research Laboratory, Department of Atmospheric and Oceanic Science, \\ The University of Michigan, Ann Arbor, MI 48109, U.S.A.
}

(Received 6 September; in revised form 10 December, 1985)

\begin{abstract}
This paper uses arguments of geochemical mass balance to arrive at an estimate of the partial pressure of carbon dioxide in the terrestrial atmosphere very early in earth history. It appears that this partial pressure could have been as large as 10 bars. This large estimate depends on two key considerations. First, volatiles were driven out of the interior of the earth during the course of earth accretion or very shortly thereafter. This early degassing was a consequence of rapid accretion, which gave the young earth a hot and rapidly convecting interior. Second, the early earth lacked extensive, stable continental platforms on which carbon could be stored in the form of carbonate minerals for geologically significant periods of time. In the absence of continental platforms on the early carth, the earth's carbon must have been either in the atmosphere or ocean or in the form of shortlived sedimentary deposits on ephemeral sea floor.
\end{abstract}

\section{Introduction}

A widely accepted scenario for the origin of the atmospheres of the inner planets holds that they were released from the planetary interiors rapidly and very early in the history of the solar system. As a completely separate matter it is also widely believed that the early earth lacked extensive, stable continental platforms. The implication of these two hypotheses for the history of carbon dioxide in earth's ocean and atmosphere has not previously been explored. In this paper it is argued that if these two scenarios are correct a very large partial pressure of carbon dioxide in the early atmosphere is implied. It is further argued that there is no direct evidence to show that such a large partial pressure of carbon dioxide did not exist very early in earth history. The paper therefore presents a possible scenario for the early history of atmospheric carbon dioxide, a scenario that is implied by accepted views concerning early terrestrial evolution.

\section{Degassing History}

The arguments in favor of rapid early degassing of the interior of the earth have been presented by Stevenson (1983) and others (Fanale, 1971; Walker, 1977a, b). Modern ideas on this subject contrast with the view originally presented by Rubey (1951) of a gradual release of volatiles from the interior of the earth over the course of its history. These different views are a consequence of different ideas concerning the rate of accretion of the inner planets and their internal temperatures soon after accretion. The old view was that the planets accreted slowly, with little accretional heating of the interior, and that they warmed up and degassed over the course of planetary 
history as a result of radioactive heating of the interior (MacDonald, 1959). Modern dynamical calculations suggest that accretion was rapid and the burial of accretional energy yielded hot, convecting planetary interiors (Wetherill, 1980). Convective motion of the earth's interior would have brought all portions of the mantle close to the surface in a relatively short period of time, geologically speaking. This hot mantle material, exposed to low pressures near the surface, would have released its volatiles (Ringwood, 1979; Walker, 1982b; Lewis, 1984).

Whether the carbon would have been released initially as carbon dioxide, carbon monoxide, or methane would have depended on the oxidation state of the upper manthe at the time of degassing (Holland, 1962, 1964, 1984; Chang, 1983). This, in turn, is mainly a question of the relative timing of degassing and formation of the core. In any event, it seems clear from photochemical calculations that any reduced carbon species in the atmosphere would have been rapidly oxidized by photochemical reactions involving water vapor and its photolysis products (Kuhn and Atreya, 1979; Kasting et al., 1983). Rapid early degassing combined with photochemical reactions in the atmosphere should have yielded a situation soon after the formation of the earth in which most of earth's carbon was in oxidized form at the surface, in either ocean or atmosphere or as carbonate minerals in sediments. It is possible that carbon has returned from the surface (exogenic system) to the interior during the course of earth history as internal temperatures have decreased (Walker, 1978; Arrhenius, 1981; DesMarais, 1985).

\section{Carbon Reservoirs}

Table I presents estimates of the amounts of carbon in various reservoirs of the exogenic system (Ronov and Yaroshevsky, 1967, 1969). These data show that most of the carbon in the exogenic system (ocean, atmosphere, and sedimentary rocks) is stored on stable continental platforms in the forms of sedimentary rocks and metamorphosed sediments. The mass of carbon in sea floor abyssal sediments is less than a tenth of the total mass. The contributions of oceans and atmosphere are very much smaller still. The relative abundance of carbon on the continental platforms is, of course, a consequence of their stability. They provide a storage place for carbon with a long life in geological terms. The sea floor, on the other hand, is ephemeral. In a relatively short period of time, approximately 60 million years on average today

TABLE I

Earth's carbon stores (gr C)

\begin{tabular}{ll}
\hline Continental sediments & $8 \times 10^{22}$ \\
Continental metasediments & $1 \times 10^{22}$ \\
Abyssal sediments & $4 \times 10^{21}$ \\
Ocean & $4 \times 10^{19}$ \\
Atmosphere & $7 \times 10^{17}$ \\
Mantle & $?$ \\
\hline
\end{tabular}


(Sprague and Pollack, 1980; Sclater et al., 1981), sea floor returns to the mantle by way of subduction. Its sediments are subjected to high temperatures, and carbonate minerals are largely decarbonated. Some fraction of the carbon dioxide presumably is stored in the mantle. The rest is returned to the atmosphere and ocean as a component of volcanic and metamorphic emanations.

The distribution of exogenic carbon would have been quite different in a world without extensive continental platforms. For the present argument, the important feature of continental platforms is their long term stability, not the fact that they underlie shallow oceans. There are diverse lines of evidence that indicate that the growth of earth's continents occurred some time after the formation of the earth, with a period of most rapid growth between about three and two billion years ago (Knoll, 1984; Trendall, 1984). Sedimentological evidence has been reviewed by Lowe $(1980,1982)$. The oldest sediments are chemically and physically immature. They do not include the products of the weathering and erosion of continents. Instead, they look more like the products of erosion of young volcanic islands. The oldest sediments do not appear to have been deposited on stable, horizontal platforms. Isotopic and geochemical evidence has been reviewed by Veizer $(1976,1983)$ and colleagues (Veizer et al., 1982). The record of the strontium isotopic composition of sea water, preserved in carbonate minerals, for example, shows no evidence of a significant continental influence on the composition of sea water prior to about three billion years ago. A similar change in the provenance of shales has been demonstrated by McLennan and Taylor $(1982,1983)$ and McLennan et al. (1983) using data on the concentrations of rare earth elements. The oldest shales lack evidence of a significant contribution from the erosion and weathering of continental rocks. Data on the ages of clastic sedimentary rocks lead to the same conclusion (McCulloch and Wasserberg, 1978; Claoue-Long et al., 1984; Frost and O'Nions, 1984). Samariumneodymium dates are used to determine when the material of the rocks concerned first left the mantle and became part of the crust. Other dating techniques are used to determine the so-called stratigraphic age of the rocks, which is the age at which the material was deposited as a sedimentary rock where it is now found. Rocks of Archean age show negligible difference between their stratigraphic ages and their crustal residence ages. Rocks of Proterozoic and Phanerozoic age show an increasing time interval separating their crustal residence ages from their stratigraphic ages. The implication is that the younger rocks have been formed to a significant extent by the erosion and redeposition of significantly older crustal material, including old sedimentary rocks. The Archean rocks, on the other hand, are largely first cycle (Veizer and Jansen, 1979). They were formed from material that had only recently entered the crust and they contain little contribution from significantly older crustal material. Presumably there was not much older material in the crust to contribute to the Archean sedimentary rocks.

So, if the early earth lacked extensive continents, the very large mass of carbon that is presently stored in sedimentary rocks on the continents must have been distributed in the other reservoirs of the exogenic system, namely atmosphere, ocean, and sea 
floor sediments. We do not know whether significant quantities of carbon have returned to the mantle from the exogenic system during the course of earth's history because there are insufficient data on carbon concentrations in mantle materials (Mathez et al., 1984). For purposes of the present estimate, I shall assume that there is not a lot of carbon in the mantle today. If this assumption is incorrect, and if indeed mantle carbon was originally degassed and subsequently returned to the mantle, then there would have been even more carbon in the exogenic system than the values I assume in the estimates that follow. In other words, I shall present a lower limit for the carbon content of the exogenic system soon after the formation of the Earth.

\section{Carbon on an Earth Without Continents}

Early in earth history, therefore, there were approximately $10^{23}$ gr of carbon, possibly more, in the form of carbon dioxide in the atmosphere, carbonate and bicarbonate ions in the ocean, and carbonate minerals on the sea floor. The amount of carbon in these reservoirs has decreased over time as the continents have grown, providing a long term store for most of this carbon. Further decrease with time may have resulted from the transfer of an increasing fraction of earth's carbon to a cooling mantle. It is just possible that an increasing ability of the mantle to retain carbon combined with a growing long-lived store of carbon on the continents could have led to a temporary maximum in the carbon content of the mantle at a time just before the continental store became significant. Some evidence for a maximum in the concentration of carbon in the mantle between 3 and $3.5 \times 10^{9} \mathrm{yr}$ ago has been presented by Richardson et al. (1984) and Rogers and Hawkesworth (1984), based on the ages of diamonds.

The amount of carbon that can be stored on ephemeral sea floor is limited by the lifetime of the sea floor and by the rate of precipitation of carbonate minerals. The rate of precipitation of carbonate minerals is limited, in turn, by the rate of supply of cations with which dissolved carbonate can react (Walker, 1983b). On the early earth the cations of greatest interest were probably calcium, magnesium, and iron (Walker and Brimblecombe, 1985). On a world without continents, these cations were presumably provided by leaching of the sea floor itself. If the concentration of bicarbonate ions in sea water was very large it seems likely that hydrothermal reactions between hot basalt and sea water would have stripped almost all of the carbon from the reacting sea water. Essentially complete consumption of the bicarbonate would result because dissolution of silicate minerals would release cations to solution, thereby increasing the alkalinity of the reacting water, increasing the $\mathrm{pH}$, and therefore increasing the ratio of carbonate to bicarbonate ions. Complete consumption would have been further promoted by the decrease of the solubility of carbonate minerals with increasing temperature. That carbon is not largely removed from hydrothermally interacting sea water today is a consequence of the small concentration of carbonate and bicarbonate ions.

If it is assumed that hydrothermal interactions on the sea floor would have remov- 


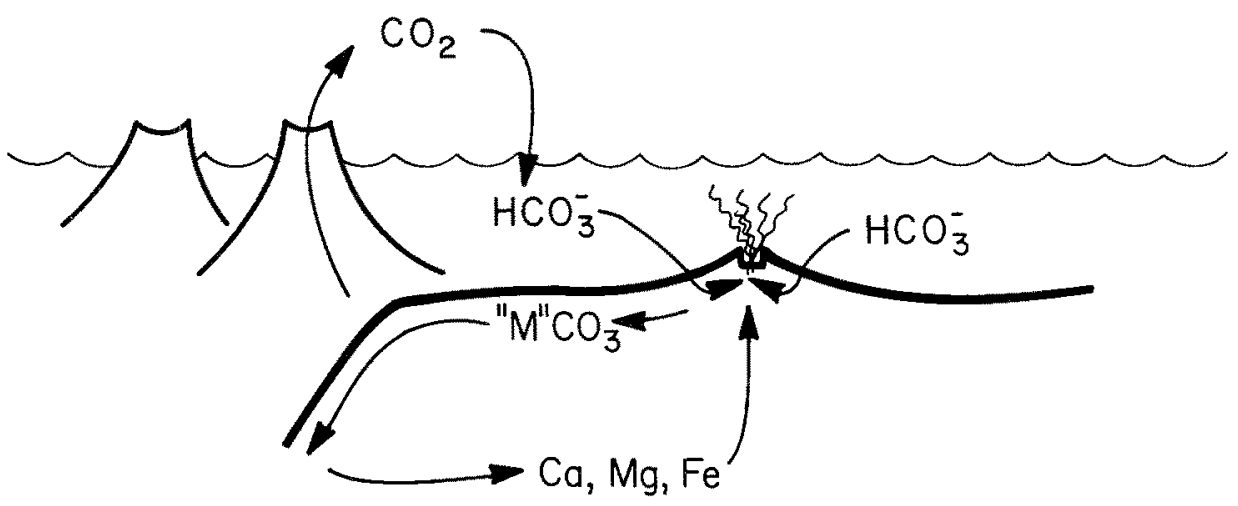

Fig. 1. Schematic representation of the presumed geochemical cycles of carbon on the early earth. Carbon dioxide is released by volcanic and metamorphic processes that decarbonate weathered sea floor. Carbon is removed from ocean and atmosphere by hydrothermal interaction with the sea floor. The symbol ' $M$ ' refers to the cations with which carbonate can react.

ed the bulk of the dissolved carbon from the reacting sea water, then the residence time of carbon in the early ocean would have been equal to the residence time of sea water between passages through hydrothermal systems. Today this residence time is estimated to be about 10 million years (Wolery and Sleep, 1976; Sleep and Wolery, 1978; Jenkins et al., 1978; Edmond et al., 1979; Lupton and Craig, 1981; Craig and Lupton, 1981). Because of higher heat flow from the early earth the residence time between hydrothermal interactions was presumably shorter.

According to this view, then, carbon would have been transferred from the fluid reservoir of ocean and atmosphere to the solid reservoir of carbonate minerals on and in the sea floor with a residence time of less than 10 million years as a result of hydrothermal interactions of sea water with hot sea floor. Extensive carbonation of sea floor basalts would have resulted; such carbonated rocks do indeed seem to be prevalent in the Archean period. After a relatively short period of time, in geological terms, carbonated sea floor would have been returned to the mantle by whatever tectonic processes prevailed on the early earth (Kerr, 1978). High temperatures would have decomposed the carbonate minerals, returning cations to silicate minerals in the mantle and carbon dioxide to the fluid phase in the form of volcanic and metamorphic emanations. Today the average age of sea floor upon subduction is 60 million years (Sprague and Pollack, 1980; Sclater et al., 1981). It would presumably have been smaller on the early earth as a result of higher heat flow. As a first approximation I shall assume that higher heat flow reduced both the residence time of sea water against hydrothermal interactions and the lifetime of sea floor before return to the mantle in the same ratio. This ratio is $6: 1$ today. I assume that it was $6: 1$ also on the early earth. If carbon cycled between the fluid phase (ocean and atmosphere) and the sea floor and back again, spending six times as long on the sea floor as in the ocean and atmosphere, then $85 \%$ of the carbon in the system would have been on 


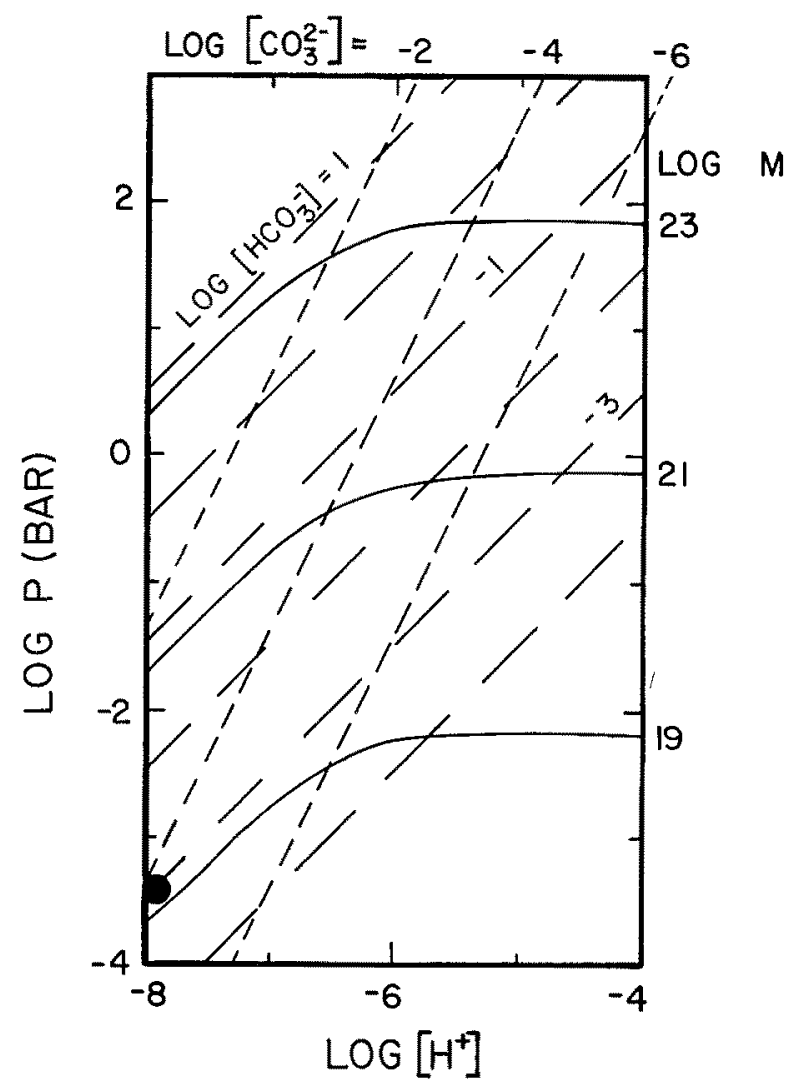

Fig. 2. Thermodynamic equilibrium concentrations of dissolved bicarbonate $(-\ldots \ldots \ldots \ldots+\ldots)$ and carbonate (- - - - - ) ions (logarithmic scales) as functions of carbon dioxide partial pressure and the concentration of hydrogen ions (Walker, 1983a). The dot marks the present day average ocean. The solid lines denote constant total mass $(\mathrm{M})$ of carbon in ocean and atmosphere combined.

the sea floor and $15 \%$ would have been in the ocean and atmosphere. This geochemical cycle is illustrated schematically in Figure 1. As a very rough estimate, therefore, I conclude that ocean and atmosphere combined contained approximately $10^{22} \mathrm{gr}$ of carbon when the Earth was young. As Table I shows, this is more than 100 times as much carbon as in the present ocean and atmosphere. The decrease with time in the carbon content of ocean and atmosphere has been a consequence of the growth of continents and the large carbon reservoir that they support.

The partitioning of this $10^{22} \mathrm{gr}$ of carbon between ocean and atmosphere would, of course, have depended on the $\mathrm{pH}$ of the ocean. Equilibria in the carbonate system are illustrated in Figure 2 as functions of $P$, the partial pressure of carbon dioxide in bars, and the concentration of hydrogen ions in sea water. Both scales are logarithmic. The dashedlines denote lines of constant concentration of carbonate and bicarbonate ions. The black dot shows approximately the average composition of the 
present day ocean. The solid lines on this figure, labelled $\log M$, are lines of constant total mass of carbon in ocean and atmosphere combined. The units are grams of carbon. In calculating these lines it is assumed that the total mass of the ocean has not changed with time, consistent with the arguments in favor of early total degasssing of the earth. At high pH (small concentration of hydrogen ions), carbon exists mainly as bicarbonate ions in the ocean and the lines of constant mass are parallel to the lines of constant bicarbonate concentration. At low $\mathrm{pH}$, carbon exists mainly as carbon dioxide in the atmosphere and, on this plot, the lines of constant mass are horizontal.

Since we may reasonably suppose that this early ocean, rich in carbonic acid, had higher hydrogen ion concentration than the modern ocean (lower $\mathrm{pH}$ ) it looks as though a total mass of carbon in ocean and atmosphere combined of $10^{22}$ gr would have yielded a carbon dioxide partial pressure close to 10 bars. If oceanic $\mathrm{pH}$ were 6 , for example, the partial pressure of carbon dioxide would be 8 bars and the carbonate concentration in sea water would be $10^{-4}$ moles per liter, close to the modern value. This high carbon dioxide partial pressure need not, therefore, have yielded an ocean undersaturated with respect to calcium carbonate. More precise statements are not possible without better understanding of the processes that control oceanic $\mathrm{pH}$. Even if $\mathrm{pH}$ were equal to its modern value of about 8 , the partial pressure of carbon dioxide would have been $200 \mathrm{mb}$. Such an ocean, however, would have been very rich in carbonate ions, supersaturation with respect to a range of carbonate minerals might have resulted.

While this hypothetical ocean under an atmosphere containing 10 bars of $\mathrm{CO}_{2}$ could have had carbonate ion concentrations close to those of the present day, it obviously had very much larger bicarbonate concentrations. Figure 2 shows an increase in bicarbonate concentration by a factor of more than 100 . This does not seem to present overwhelming problems in marine chemistry. Figure 3 shows one example of a possible composition for the major elements in sea water. This composition contains the required abundance of bicarbonate ions and achieves charge balance by increasing the concentration of sodium ions. Minor changes in the concentrations of other constituents of sea water are suggested, but are not central to the arguments presented here. The ocean illustrated in Figure 3 would not have been supersaturated with respect to minerals that are not seen in the sedimentary rock record. On the other hand the excess of total carbon over calcium could have resulted in evaporitic deposition of such carbonate minerals as magnesite $\left(\mathrm{MgCO}_{3}\right)$, which is present in sedimentary rocks of Archean age (McGregor and Bliss, 1968; Perry and Tan, 1972).

\section{Implications of Large Carbon Dioxide Partial Pressure}

The proposed large partial pressure of carbon dioxide on the early earth would obviously have had a significant impact on the average surface temperature of the globe and the thermal structure of the atmosphere as a result of the infra-red absorption properties of carbon dioxide. Large concentrations of carbon dioxide in the atmosphere would have yielded a larger greenhouse effect and a warmer surface (Owen 


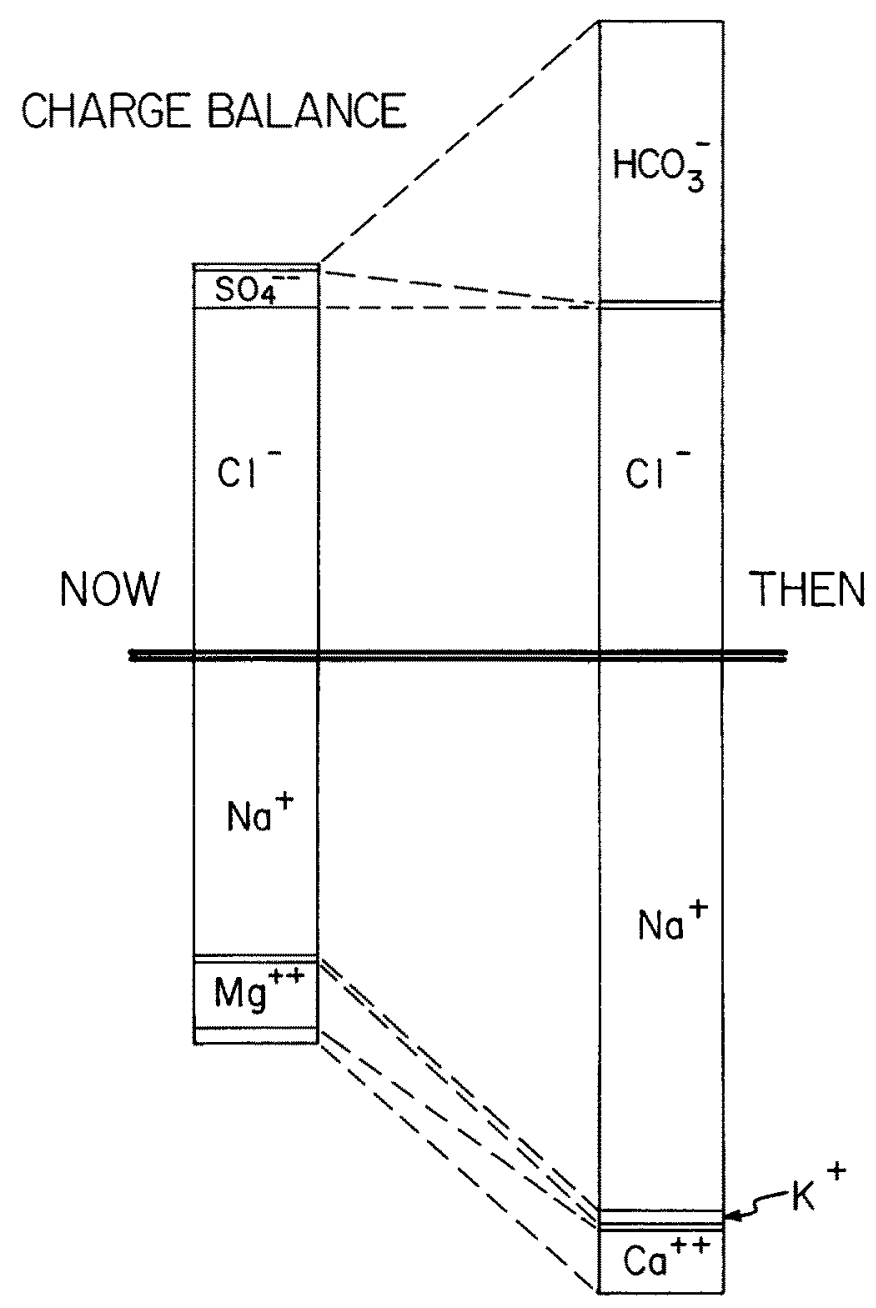

Fig. 3. Comparison of the possible composition of the early ocean with the composition of the modern ocean.

et al., 1979; Walker, 1982a; Kuhn and Kasting, 1983). In particular, it might be wondered whether 10 bars of carbon dioxide would lead to a runaway greenhouse effect (Ingersoll, 1969), in which either the oceans completely evaporated leaving no liquid water on the surface or there was so much water vapor in the upper atmosphere that very large fluxes of hydrogen escaped from the earth to space leaving the earth, eventually, without any water. Such a runaway greenhouse effect is believed to have resulted in the loss of water from Venus (Pollack, 1971; Walker, 1975; Donahue et al., 1982; Kasting et al., 1984). I am indebted to James Kasting (personal communication) of the NASA Ames Research Center for the results of calculations of the 
temperature structure in the early atmosphere of the Earth with a presumed 10 bar partial pressure of $\mathrm{CO}_{2}$. Kasting's computational methods and model have been described (Kasting and Pollack, 1984). His results show that while this much carbon dioxide leads to a hot earth, it is not so hot as to cause a runaway greenhouse effect. The difference between Venus and Earth in this respect is that Venus, being closer to the Sun, receives twice as much energy as the Earth.

While carbon dioxide partial pressures were initially large, according to the model I have presented, they would have declined rapidly as a result of the growth of continents and the growth of the global sedimentary rock reservoir and possibly also as a result of the return of carbon from the exogenic system to the mantle. The time scale for such a decline is not known, but the situation 1 have described clearly applies to the Archean earth and not to more recent earth history. Very early in earth history (during the Hadean) very large accretionary impacts may have decarbonated such carbonate rich sediments as existed, further increasing the partial pressure of carbon dioxide. Controls on carbon dioxide partial pressure after the emergence of continents have been discussed by Walker et al. (1981). By the end of the Archean, with a continental reservoir not markedly less than that of today, carbon dioxide partial pressures are not likely to have exceeded 100 millibars. Further decrease with time in the carbon dioxide partial pressure has been a consequence, according to Walker et al. (1981), of increasing solar luminosity and therefore an increasing rate of reaction between carbon dioxide and silicate minerals on the continents.

\section{Acknowledgements}

I thank J. F. Kasting for the results of calculations of the climatic consequences of high carbon dioxide partial pressures and M. R. Walter for stimulating my interest in the geologic history of atmospheric carbon dioxide. This paper describes research supported in part by the National Science Foundation under Grant ATM-8209760 to The University of Michigan. It is a contribution of The Precambrian Paleobiology Research Group.

\section{References}

Arrhenius, G: 1981, Adv. Space Res. 1, 37.

Chang, S., DesMarais, D., Mack, R., Miller, S. L., and Strathearn, G. E.: 1983, in J. W. Schopf (ed.), Earth's Earliest Biosphere, Princeton University Press, p. 53.

Claoue-Long, J. C., Thirlwall, M. F., and Nesbitt, R. W.: 1984, Nature 307, 697.

Craig, H. and Lupton, J. E.: 1981, in The Sea, Vol. 7, The Oceanic Lithosphere, John Wiley and Sons, p. 391.

DesMarais, D. J:- 1985, in E. T. Sundquist and W. S. Broecker (eds.), The Carbon Cycle and Atmospheric $\mathrm{CO}_{2}$, American Geophysical Union, Washington, D.C., p. 602.

Donahue, T. M., Hoffman, J. H., Hodges, Jr., R. R., and Watson, A. G.: 1982, Science 216, 630.

Edmond, J. M., Measures, C., McDuff, R. E., Chan, L. H., Collter, R., Grant, B., Gordon, L. I., and Corliss, J. B.: 1979, Earth Planet. Sci. Letters 46, 1.

Fanale, F. P.: 1971, Chemical Geology 8, 79. 
Frost, C. D. and O'Nions, R. K.: 1984, Nature 312, 53.

Holland, H. D.: 1962, in A. E. J. Engle, H. L. James, and B. F. Leonard (eds.), Petrologic Studies: A Volume in Honor of A. E. Buddington, Geological Society of America, New York, p. 447.

Holland, H. D.: 1964, in P. J. Brancazio and A. G. W. Cameron (eds.), The Origin and Evolution of Atmospheres and Oceans, John Wiley and Sons, New York, p. 86.

Holland, H. D.: 1984, The Chemical Evolution of the Atmosphere and Oceans, Princeton University Press, Princeton, N.J.

Ingersoll, A. P.: 1969, J. Atmos. Sci. 26, 1191.

Jenkins, W. J., Edmond, J. M., and Corliss, J. B.: 1978, Nature 272, 156.

Kasting, J. F. and Pollack, J. B.: 1984, J. Atmospheric Chemistry 1, 403.

Kasting, J. F., Pollack, J. B., and Ackerman, T. P.: 1984, Icarus 57, 335.

Kasting, J. F., Zahnle, K. J., and Walker, J. C. G.: 1983, Precambrian Res. $20,121$.

Kerr, R. A.: 1978, Science 199, 282.

Knoll, A. H.: 1984, in H. D. Holland and A. F. Trendall (eds.), Patterns of Change in Earth Evolution, Springer-Verlag, Berlin, p. 221.

Kuhn, W. R. and Atreya, S. K.: 1979, Icarus 37, 207.

Kuhn, W. R. and Kasting, J. F.: 1983, Nature 301, 53.

Lewis, J. S. and Prinn, R. G.: 1984, Planets and their Atmospheres, Academic Press, New York.

Lowe, D. R.: 1980, Ann. Rev. Earth Planetary Sci. 8, 145.

Lowe, D, R.: 1982, Precambrian Res. 17, 1.

Lupton, J. E. and Craig, H.: 1981, Science 214, 13.

MacDonald, G. J. F.: 1959, J. Geophys. Res. 64, 1967.

MacGregor, B. I. and Bliss, N. W.: 1968, Geol. Soc. South Africa Trans. 71 (Annexure), 159.

Mathez, E. A., Blacic, J. D., Berry, J., Maggiore, C., and Hollander, M.: 1984, Geophys. Res. Letters $11,947$.

McCulloch, M. T. and Wasserburg, G. J.: 1978, Science 200, 1003.

McLennan, S. M. and Taylor, S. R.; 1982, J. Geol. 90, 347.

McLennan, S. M. and Taylor, S. R.: 1983, Nature 306, 169.

McLennan, S. M., Taylor, S. R., and Kroner, A.: 1983, Precambrian Res. 22, 93.

Owen, T., Cess, R. D., and Ramanathan, V.: 1979, Nature 277, 640.

Perry, E. C. and Tan, F. C.: 1972, Geol. Soc. Am. Bull. 83, 647.

Pollack, J. B.: 1971, Icarus 14, 295.

Richardson, S. H., Gurney, J. J., Erlank, A. J., and Harriss, J. W.: 1984, Nature 310, 198.

Ringwood, A. E.: 1979, Origin of the Earth and Moon, Springer-Verlag, New York.

Rogers, N. and Hawkesworth, C.: 1984, Nature 310, 187.

Ronov, A. B. and Yaroshevskiy, A. A.: 1967, Geochemistry 11, 1041-1066. (Translated from Geokhimiya 11, 1285, 1967.)

Ronov, A. B. and Yaroshevsky, A. A.: 1969, in P. J. Hart (ed.), The Earth's Crust and Upper Mantle, Am. Geophys. Union Monograph 13, Washington, p. 37.

Rubey, W. W.: 1951, Bull. Geol. Soc. Am. 62, 11.

Sclater, J. G., Parsons, B., and Jaupart, C.: 1981, J. Geophys. Res. 86, 11535.

Sleep, N. H. and Wolery, T. J.: 1978, J. Geophys. Res. 83, 5913.

Sprague, D. S. and Pollack, H. N.: 1980, Nature 285, 393.

Stevenson, D. J.: 1983, in J. W. Schopf (ed.), Earth's Earliest Biosphere, Princeton University Press, p. 32.

Trendall, A. F.: 1984, in H. D. Holland and A. F. Trendall (eds.), Patterns of Change in Earth Evolution, Springer-Verlag, Berlin, p. 243.

Veizer, J.: 1976, in B. F. Windley (ed.), The Early History of the Earth, John Wiley and Sons, London, p. 569.

Veizer, J.: 1983, in J. W. Schopf (ed.), Earth's Earliest Biosphere, Princeton University Press, p. 240.

Veizer, J. and Jansen, S. L.: 1979, J. Geology 87, 341.

Veizer, J., Compston, W., Hoefs, J., and Nielsen, H.: 1982, Naturwissenschaften 69, 173.

Walker, J. C. G.: 1975, J. Atmos. Sci. 32, 1248.

Walker, J. C. G.: 1977a, in C. Ponnamperuma (ed.), Chemical Evolution of the Early Precambrian, Academic Press, New York, p. 1.

Walker, J. C. G.: 1977b, Evolution of the Atmosphere, Macmillan Publishing Co., New York.

Walker, J. C. G.: 1978, in C. Ponnamperuma (ed.), Comparative Planetology, Academic Press, New York, p. 141. 
Walker, J. C. G.: 1982a, Paleogeography, Paleoclimatology, Paleoecology 40,1.

Walker, J. C. G.: 1982b, Precambrian Res. 17, 147.

Walker, J. C. G.: 1983a, Nature 302, 518.

Walker, J. C. G.: 1983b, Nature 303, 730.

Walker, J. C. G. and Brimblecombe, P.: 1985, Precambrian Res. 28, 205.

Walker, J. C. G., Hays, P. B., and Kasting, J. F.: 1981, J. Geophys. Res. 86, 9776.

Wetherill, G. W.: 1980, Ann. Rev. Astron. Astrophys. 18, 77.

Wolery, T. J. and Sleep, N. H.: 1976, J. Geol. 84, 249. 